\title{
Transgredindo as margens e forjando histórias: a imprensa negra na fronteira Brasil-Uruguai no pós-abolição *
}

\author{
Transgressing the margins and forging stories: the black press on the Brazil-Uruguay \\ border in the post-abolition
}

Fernanda Oliveira da Silva

\author{
Doutora em História \\ Pós-doutoranda em História pela \\ Universidade Federal Rural do Rio de Janeiro \\ fernandaoliveira4p@gmail.com
}

\begin{abstract}
Resumo: Neste artigo analiso a imprensa negra da região de fronteira Brasil-Uruguai, mais especificamente das cidades de Melo e Pelotas: A Alvorada (Pelotas, 1907-1965), Acción (Melo, 1934-1952) e Orientacion (Melo, 19411945). A experiência destes periódicos é o fio condutor, cujo foco está em Acción, criado como porta voz do Centro Uruguay, clube negro criado em Melo em 1923. Dentre as conclusões explicito que por meio da tribuna pública, imprensa, foram transgredidas as margens, tanto uma referência aos trânsitos em uma região de fronteira, quanto às vivências da racialização, e forjada uma história para a nação uruguaia que se conectava com o Brasil, denunciava a racialização reinante e inseria a população negra dentre os atores daquela história já plenamente conhecida pelos pagos uruguaios.
\end{abstract}

Palavras-chave: imprensa negra, fronteira, pós-abolição.
Abstract: In this article, I analyze the black press from the Brazil-Uruguay border region, more specifically from the cities of Melo and Pelotas: A Alvorada (Pelotas, 1907-1965), Acción (Melo, 1934-1952) and Orientacion (Melo, 1941-1945). The experience of these periodicals is the thread, whose focus is on Acción, created as the mouthpiece of the Centro Uruguay, black club created in Melo in 1923. Among the conclusions explicitly stated that through the public gallery, press, the margins were transgressed, both a reference to the transits in a frontier region, regarding the experiences of racialization, and forged a history for the Uruguayan nation that connected with Brazil, denounced the reigning racialization and inserted the black population among the actors of that history already wellknown for the payments Uruguayans.

Keywords: black press, border, post-abolition

\footnotetext{
* A análise aqui desenvolvida é parte da tese de doutorado intitulada As lutas políticas nos clubes negros: culturas negras, racialização e cidadania na fronteira Brasil-Uruguai no pós-abolição (1870-1960).
} 
Nas páginas dos representantes da imprensa negra na região fronteiriça $A$ Alvorada, Acción e Orientacion publicavam-se parte considerável da programação dos clubes negros criados em Pelotas, Bagé, Melo e Jaguarão e, não raras vezes, eram seus porta-vozes oficiais. ${ }^{1}$ É sobre a experiência destes periódicos, mantendo o foco no Acción, criado em 1934 como porta voz do Centro Uruguay, que lanço o olhar nesse capítulo.

As cidades do interior não ficaram de fora do circuito que movimentava as capitais, no caso do Brasil, por vezes sediaram representantes do órgão que circulava na capital do Estado. Antes disso, tiveram suas próprias experiências, como foi o caso de Pelotas, na qual foi lançado o periódico A Voz do Escravo, em 1881, de caráter abolicionista. E, em 1886, o Ethiópico, como abordou Beatriz Ana Loner em sua vasta produção historiográfica. ${ }^{2}$ Não obstante, e ainda na esteira da produção de Loner, a imprensa negra e as demais associações de recorte racial compunham o cerne do associativismo negro na interiorana e ainda aristocrática Princesa do Sul. ${ }^{3}$ Em tese de doutorado estendi o seu argumento para os clubes e os periódicos negros, entendidos como a centralidade da sociabilidade negra no pós-abolição (SILVA, 2017). Fora nessa ceara que as experiências negras que aqui acompanhamos estabeleceram-se e teceram suas relações, especialmente na primeira metade do século XX.

Explícito que deparei-me com a sociabilidade negra uruguaia por intermédio da imprensa negra de Pelotas, mais precisamente, do jornal A Alvorada. Ao tomar conhecimento da historiografia sobre a presença negra na América Latina, as referências eram principalmente sobre Montevidéu, porém, já apontavam para a existência de uma organização negra no interior, na fronteira com o Brasil. As fontes para tratar do associativismo negro no pós-abolição nem sempre são de fácil localização, uma vez que não necessariamente se encontram em arquivos públicos. Mas, para minha felicidade, encontrei na hemeroteca da Biblioteca Nacional do Uruguai dois periódicos negros da cidade de Melo: Acción e Orientacion.

Para compreender o circuito em que estes jornais estavam imersos é necessário traçar um parêntese a fim de localizar as discussões acerca da identificação imprensa

\footnotetext{
${ }^{1}$ O jornal Acción apresentou I época: 1934-1935, II época: 1944-1946, III Época: 1947-1950, IV Época: 1950-1952. A Alvorada circulou na $1^{\text {a }}$ fase: 1907-1935; $2^{\text {a }}$ fase (nova fase): 1946-1965. Orientacion apresentou I época: 1941-1944 e II época: 1944-1945. As coleções de jornais uruguaios foram acessadas na Biblioteca Nacional do Uruguai (Montevidéu) e em acervos privados na cidade de Melo, as de $A$ Alvorada foram consultadas na Biblioteca Pública Pelotense, Clube Cultural Fica Ahí P'rá Ir Dizendo e Núcleo de Pesquisas Históricas da UFRGS.

${ }^{2}$ LONER, 2009: 246-261; 2011: p. 109-136; 2001; \&Gill, 2009: p. 145-162.

${ }^{3}$ Epíteto para Pelotas.
} 
negra conferida pela historiografia a estes moldes de periódicos. Esta, de acordo com as análises de historiadores que dialogam no campo dos estudos do pós-abolição, como Amilcar Pereira (2013), Ana Flávia Magalhães Pinto (2010, 2014), Giovana Xavier (2012) e José Antonio dos Santos (2003), é entendida a partir de suas características, ou seja, ela é produzida, em especial, por pessoas autoidentificadas como racialmente negras, voltada a um público predominantemente negro, e cujos assuntos tratados têm recorte explicitamente racial, mas não exclusivo, privilegiando escritos sobre cidadania; liberdade; efeitos da violência de caráter coletivo, estrutural, e individual e diálogos com pessoas negras de outras nações, sobretudo, no século XX.

As pesquisas acadêmicas que problematizaram a imprensa negra como objeto de estudo datam de 1951, abordando questionamentos próprios do fazer sociológico, como as de Roger Bastide (1973) concentrado nas experiências da cidade de São Paulo a partir da problematização de uma consciência coletiva negra. Um segundo intento, que dialoga de forma mais estreita com as pesquisas do campo acima referido, data de 1980, com a dissertação de Miriam Nicolau Ferrara (1986), concentrada também em São Paulo, e investigando a cidadania reivindicada nas páginas dos jornais editados entre 1915 e 1963 , atentando ainda para o continente mãe, a África. Os dois trabalhos contemplaram o período do pós-abolição, assim como a dissertação de mestrado em História de José Antonio dos Santos, publicada em livro no ano de 2003, a primeira investigação sistemática sobre o jornal A Alvorada, contemplando toda a existência do jornal (19071965). O historiador realizou uma análise centrada nos intelectuais negros redatores do jornal, enfatizando seus laços com o movimento operário, nos rastros daquilo que Beatriz Ana Loner destacou em sua tese (2001).

Por sua vez, a dissertação de mestrado de Ana Flávia Magalhães Pinto (2010), marcou uma reconfiguração no campo de pesquisas, ao imergir nas fontes do século XIX e apresentar questões presentes em páginas editadas desde 1833, como liberdade, abolicionismo e letramento. Se, até então, questões como branqueamento e inserção social no meio branco eram agendas de pesquisa bem consolidadas, a análise explicita a necessidade de perscrutar os sentidos de liberdade presentes na escrita daqueles jornalistas negros, provocando uma reconfiguração da agenda de pesquisas da imprensa negra. A pesquisa de Magalhães Pinto oferece subsídios mais que consistentes para evidenciar a noção de precariedade estrutural da liberdade negra que se consolidava na historiografia brasileira, sobretudo naquela advinda dos estudos centrados nos mundos do trabalho (LIMA, 2005; CHALLOUB, 2010). 
Embora não tenham ficado restritas ao estudo da imprensa negra e, tampouco ao território brasileiro, as pesquisas de doutorado de Amilcar Pereira (2013) e Giovana Xavier (2012) são aqui entendidas como contribuindo para essa virada epistemológica no que tange à própria escrita da história a partir da imprensa negra. Ambos se propuseram a pensar o pós-abolição como problema histórico e utilizaram-se da imprensa negra. Pereira contemplou a constituição do movimento social negro no século XX e, para tal, fez uma imersão nas imprensas negras do Brasil e dos Estados Unidos, mais especificamente nos jornais publicados em São Paulo e Chicago. Sem perder de vista a circulação de referenciais entre eles e com África, evidenciou um trânsito que não possuía centro fixo de influência e que só pode ser entendido na circularidade, simultaneamente de notícias e pessoas negras. Xavier, por sua vez, imergiu nas fontes norte-americanas para investigar uma história social da beleza negra, entre 1890 e 1930, mostrando que foi por meio da imprensa negra que essa história pode ser escrita, fora nela que a própria história da nação norte-americana também estava escrita e forjada desde homens e mulheres negras. A investigação da participação efetiva na política por pessoas negras foi ainda desenvolvida por José Antonio dos Santos em sua tese de doutorado (2011), concentrada na imprensa negra editada no estado do Rio Grande do Sul entre os anos de 1892 a 1930.

É necessário explicitar que as questões não foram abordadas para o Uruguai, de forma sistemática, em pesquisas de mestrado e doutorado em História. Não obstante, a imprensa negra foi utilizada como fonte para mapear o associativismo negro em Montevidéu, por George Reid Andrews (2011), e, especialmente pelo musicólogo Gustavo Goldman (2015, 2016), que nos apresenta os otros ciudadanos por meio de suas músicas, além de suas escritas e intentos coletivos de cunho político institucional, como descrito pelo pesquisador. Findo o parêntese é momento de voltar a contemporaneidade dos periódicos negros da região da fronteira.

Passados dez anos da criação do Centro Uruguay, que se dera em 1923, um grupo de jovens trabalhadores negros criou o periódico Acción, dirigido por Juan Jacinto Ferrán, que por sua vez era porteiro de um dos clubes da elite melense, e que na $1^{\mathrm{a}}$ época do jornal dividia a função com Carlos M. Pérez. A primeira edição circulou em 15 de outubro de 1934 e trazia destacado, logo abaixo do nome, a seguinte descrição: “Órgano del Comité Pro Edificio del Centro Uruguay". Ou seja, o jornal era um órgão divulgador das atividades do Comitê, responsável pela arrecadação de verbas em prol da sede própria do clube e se apresentava como o órgão defensor da raza de color. Até o aparecimento de 
Acción, a capital da República uruguaia concentrava praticamente todas as experiências de imprensa negra, fosse naquele momento, fosse no passado, como exemplificado por La Conservación que circulou no ano de 1872 (SILVA, 2017). Não obstante, era uma novidade ter um órgão periódico vinculado a um clube negro no interior do país, e parece ter se transformado em uma estratégia comum das coletividades negras, como os exemplos na sequência permitirão acompanhar.

O aparecimento de Acción foi saudado pela principal revista da coletividade negra então existente, Nuestra Raza - órgano de la colectividade de color - de Montevidéu. Esta fora criada em 1917 em San Carlos, no departamento de Maldonado, pelo casal de irmãos María Esperanza Barrios e Ventura Barrios, editores aos quais logo se uniu o terceiro irmão, Pilar Barrios. ${ }^{4}$ Circulou apenas ao longo daquele ano e posteriormente, em 1933, fora republicada pelos irmãos Ventura e Pilar Barrios na capital, em conjunto com Elemo Cabral. Importa destacar que até então esta era a única experiência de imprensa negra no interior do país (ANDREWS, 2011: 137. RODRÍGUEZ, 2006: 108) A notícia do aparecimento de Acción, nas páginas de Nuestra Raza fora republicada nas páginas do órgão melense:

Ha llegado a nuestra mesa de trabajo el colega que nos sirve de epígrafe [Acción], periódico quincenal de la colectividad que ve la luz en la progresista ciudad de Melo.

Por el esfuerzo que representa, por el profundo y legítimo anhelo de elevación que traduce su programa, es digno de apoyo y merece todo estimulo.

Al agradecer el envío, deseamos al colega hermano larga y prospera vida, y dejamos establecido el canje de práctica. - 'Nuestra Raza' órgano de la colectividad de color - Montevideo, Noviembre, 23 de 1934. (Acción, 30 de novembro de 1934: 3 )

\footnotetext{
${ }^{4}$ Pilar E. Barrios (1889-1974) nasceu no departamento de Rocha (Uruguai), frequentoua escola por seis meses, trabalhador de estâncias, começou a produzir os primeiros versos em 1907. Dentre suas publicações estão Piel Negra (1947), Mis Cantos (1949) e Campo Afuera(1958), todos eles marcados pela temática racial. $\mathrm{O}$ autor estabeleceu relação com vários intelectuais negros nas Américas, dentre eles os poetas Langston Hughes (estadunidense), Nicolás Guillén (cubano) e Jacques Roumain (haitiano); assim como com as artistas estadunidenses Marian Anderson e Kaherine Dunham e com a antropóloga estadunidense Irene Diggs. Na edição de 15 de fevereiro de 1935 do jornal Acción, o poeta residente em Montevidéu, foi saudado como colaborador Nuevo Colaborador. Além de se deslocar a Melo em vários momentos e desenvolver atividades em prol do clube, o poeta auxiliava o Centro Uruguay financeiramente, como evidenciado nas páginas de Acción (SERRAT, 2010).
} 
Tal correspondência entre representantes da imprensa negra e da imprensa de grande circulação foi notícia comum nas páginas de Acción o que demonstra que a folha era reconhecida enquanto uma experiência periódica e tinha relevância no cenário, mesmo que não tenhamos acesso à tiragem de sua publicação. Assim como o jornal circulava para além de Melo, as referências nele presentes também extrapolavam as fronteiras locais e nacionais. Denotavam os códigos e valores socializados que eram entendidos como representativos e compunham a cultura política compartilhada, mas também gestada por meio das páginas de Acción. $^{5}$

Os exemplos aqui destacados são ilustrativos dos trânsitos e valores compartilhados pelos intelectuais que compunham o Centro Uruguay, envolvidos na manutenção do jornal em seus diálogos inseridos em uma cultura política arraigada na ideia de raça negra. Destaques como estes eram comuns nas páginas de Acción, destaco as referências constantes aos poetas montevideanos colaboradores do jornal, Pilar E. Barrios e Iris Virginia Brindis de Salas, ${ }^{6}$ ao poeta e periodista cubano Nicolás Guillén. ${ }^{7}$ à jornalista norte-americana Irene $\operatorname{Diggs}^{8}$ e à invasão à Etiópia pelas tropas italianas em 1935. (Humanidad. Acción, 16 de setembro de 1935: s/p) Tais elementos colocam em perspectiva tanto a unidade dos grupos negros na diáspora, fosse dentro da fronteira nacional ou fosse através desta, mesmo em se tratando de uma cidade interiorana, assim como a rememoração e os usos do passado, abrindo uma discussão acerca da realidade dos grupos negros em outros espaços com relação à situação vivida nas suas fronteiras

\footnotetext{
${ }^{5}$ Estou informada pela noção de cultura política apregoada pelo historiador francês Serge Berstein, o qual citando Jean-François Sirinelli, destaca que: "se trata de uma espécie de código e de um conjunto de referentes, formalizados no seio de um partido ou, mais largamente, difundidos no seio de uma família ou de uma tradição políticas". Na sequência, o autor alerta: "reteremos dois factos fundamentais: por um lado, a importância do papel das representações na definição de uma cultura política, que faz dela outra coisa que não uma ideologia ou um conjunto de tradições; e, por outro lado, o carácter plural das culturas políticas num dado momento da história e num dado país". (BERSTEIN, 1998: 350).

${ }^{6}$ Virginia Brindis de Sala (1908-1958) é considerada a primeira poetisa negra do Uruguai. Nasceu em Montevidéu. "Mi Corazon", seu primeiro poema, foi publicado na edição de 25 de abril de 1944 assinado como Iris Virginia Salas. Na edição de 25 de outubro de 1945 foi publicado o poema Tus Ojos, com a assinatura Iris. No ano seguinte, a autora lançava o livro Pregón de Marimorena e, na edição de 25 de agosto de 1946,foi saudado nas páginas do jornal em matéria intitulada Virginia Brindis de Salas. Nesta foi reproduzida parte da reportagem feita pela revista Mundo Uruguayo, de Montevidéu, acerca do recente livro: "Ella interpreta a los suyos, escribe para redimir a sus hermanos [...] Porque integra 'el coro redentor' extendido desde las Antillas hasta el Río de la Plata. Y, es luz de ese coro. [...] Ella no toma lo pintoresco para jugar a la poesía, toma las esencias de su raza para alabar la libertad, que, pese las Reyes igualitarias de casi todos los Estados, todavía, es una esperanza". Existe divergência acerca do seu nome e da autoria de suas obras. Sobre isto ver: (BURGUEÑO, 2007); (DECOSTA-WILLIS, 2003).

${ }^{7}$ Nicolas Guillén (1902-1989) nasceu em Camagëy, periodista e poeta com uma gama de poesias e livros publicados.

${ }^{8}$ Irene Diggs (1906-1998) foi uma antropóloga norte-americana. Dentre suas pesquisas destaca-se o livro Black Chronology: From 4.000 BC to the Abolition of the Slave Trade, publicado em 1983. Influencias Beneficiosas. Acción, 30 de agosto de 1947, s/p.
} 
nacionais, ou seja, não era algo completamente descontextualizado, e por isso estava publicado.

A capa da edição de 27 de novembro de 1935 do jornal Acción trazia a imagem imponente do estadunidense Booker Taliaferro Washington ${ }^{9}$. (ver imagem 1) intitulada Hombres Celebres e, na sequência, um editorial assinado por Elemo Cabral, articulista da revista Nuestra Raza. Abaixo da imagem, a informação: “Booker Taliaferro Washington nació en el estado de Virginia - V. N. de América - el año de 1858 falleció el 14 de Noviembre de 1915 en Tuskegee, Alabama".

\section{Imagem 1}

Booker Taliaferro Washington.

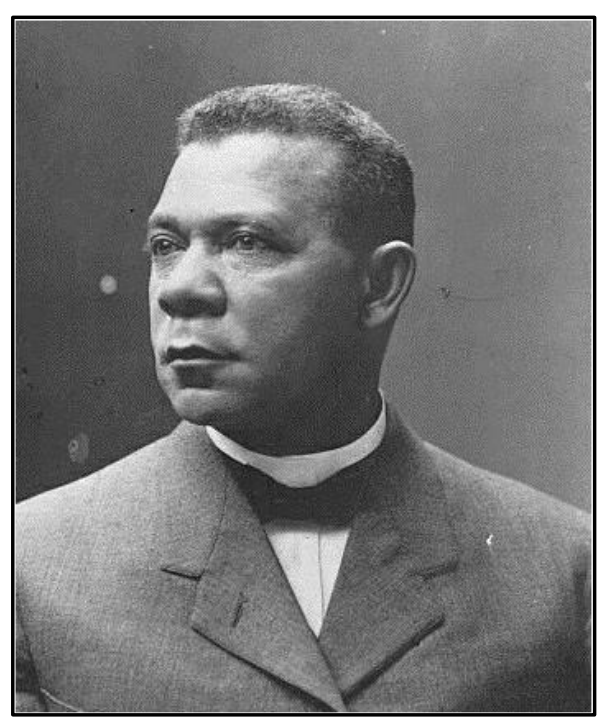

Fonte: Hombres Celebres. Acción, 27 de novembro de 1935: s/p.

\footnotetext{
${ }^{9}$ Booker Taliaferro Washington (1858-1915) foi feito escravizado ao nascer em decorrência da condição de sua mãe, após sua liberdade estudou e se tornou professor. Fundou o Tuskegee Normal and Industrial Institute, em 1881, no Alabama, em que era ofertada educação aos afro-americanos com ênfase ao aprendizado de ofícios agrícolas. Foi um importante líder em prol da educação dos grupos negros, estabelecendo alianças com lideranças políticas norte-americanas que lhe possibilitaram manter o espaço educacional. Sua filosofia estava vinculada à ótica do trabalho como forma de progresso econômico e social. No entanto, foi também contestado por outras lideranças negras como, por exemplo, W. E. B. Du Bois, que se posicionava contrário a sua estratégia de luta, visto que não se colocava abertamente contrário à segregação racial que vigorava nos estados do sul. Washington legou a história uma série de discursos e sua autobiografia, intitulada Up from Slavery, publicada em 1901. Disponível em http://pinkmonkey.com/dl/library1/slavery.pdf Acesso em: mai. 2015. Esta edição foi traduzida para o espanhol sob o título Salindo da la esclavitud, e publicada em 1905. Disponível em <http://cdigital.dgb.uanl.mx/la/1080003135/1080003135.PDF>. Acesso em: jun. 2017.
} 
O célebre homem que estampava a capa de Acción, em 27 de novembro de 1935, fora apresentado como um apóstolo da causa social, moral e econômica de uma raça, o qual, ao tecer uma parceria com Abraham Lincoln na luta pela transformação do escravo em cidadão na porção norte das Américas, havia se colocado como um cidadão defensor da democracia. No entanto, é feita a seguinte advertência: "La nueva situación de ciudadano no mejoró la inferior de esclavo; sino, al contrario: se arraigó más la lucha de razas aún existente". Esta, no contexto da escrita da nota, pode tanto referir-se à realidade norte-americana quanto à uruguaia, a partir de experiências pautadas em uma ideia de raça que Elemo, constante colaborador conrazaneo, denominação conferida aos negros no Uruguai, que significava o compartilhamento de raça, e certamente outros redatores de Acción entendiam como algo comum, compartilhado além das fronteiras nacionais, e por isto mesmo passível de estar nas páginas do jornal. A homenagem, embora assinada, é apresentada como uma mensagem coletiva advinda dos "negros del Uruguay" em honra aos 20 anos do falecimento do norte-americano feito escravizado, mas que, em liberdade, educou os seus e legou a obra Instituto Industrial de Tuskegee.

A ressalva feita em relação à situação do cidadão está em profundo diálogo com aquilo que o também norte-americano W. E. B. Du Bois, anteriormente referenciado, denominou Democracia da abolição (DAVIS, 2009: 86-86). Ou seja, os problemas da liberdade cerceavam a cidadania negra os quais ainda tinham importância e vigência, nos anos 1930, para os negros envolvidos na manutenção do periódico Acción. A escrita apresenta uma franca desnaturalização do estatuto social de cidadão. Tem-se acesso àquilo que historiadores problematizaram e serve como base para o campo de estudos do pós-abolição, a saber, os sentidos e os problemas da liberdade em que as noções de modernidade e democracia foram reivindicadas pelos quase-cidadãos ${ }^{10}$.

De forma a melhor entender o circuito cultural no qual adquiria sentido acionar a imagem do estadunidense, assim como evidenciar que tais aparições não eram exceções apresento um mapeamento da história desses periódicos. Tendo como intuito também compreender a existência de um circuito de referências negras cujas trajetórias eram apresentadas como parte de uma história conectada pela ideia de raça e que, não obstante, compunham diversas histórias nacionais inclusive a uruguaia e a brasileira. No caso aqui explicitado, a ênfase à parceria de T. Washington com Lincoln não é interpretada como algo ilustrativo, mas como uma estratégia retórica para demonstrar que o fazer parte era

\footnotetext{
${ }^{10}$ Parafraseando a expressão de Olívia Cunha e Flávio Gomes.
} 
uma construção das gentes negras. Algo almejado no pós-abolição, mesmo em nações tidas de forma geral como ainda mais democráticas que a qual pertenciam, especialmente os Estados Unidos da América. Como, por exemplo, transparece na ironia do título, No paiz da democracia, em matéria veiculada n'Alvorada sobre a demanda pelo fim da discriminação racial nas escolas norte-americanas em 1949 (A Alvorada, 19 de novembro de 1949, capa). Afinal o bastião da democracia nas Américas não era democrático quando se tratava de direitos iguais para pessoas não brancas.

Não obstante, se o problema que se observava enquanto contínuo naquela nação após a abolição, transcrito por Elemo Cabral, em 1935, e revisitado, em 1949, no editorial de A Alvorada, não era tido como uma história à parte. Evidenciado não apenas na matéria seguinte ao editorial do periódico pelotense, também compartilhando a capa, intitulada Campanha de Educação de Adultos, mas especialmente na forma como eram apresentadas as matérias acerca de outras realidades nacionais e gentes negras proeminentes nas sociedades, nomeadamente exceções que se sobressaíam frente ao racismo existente, orgulhos da raça negra que contrapuseram as margens impostas pelos estereótipos racistas. Dessa forma, compõe aquilo que entendo como a pauta central desses periódicos: a racialização. As estratégias para abordá-la povoavam as páginas dos periódicos e foram acionadas em diferentes formatos. Nestes se assegurou a identidade do indivíduo sem que se pautasse em valores individualistas, pelo contrário, centrada em uma noção de coletividade que se complementava sempre que o preconceito de raças e os efeitos estruturais de sua existência eram burlados ou postos à prova.

A complexidade dos elementos aqui destacados é constante nas páginas do jornal que circulou em Melo, entre os anos de 1934 e 1952, embora não por todo o período. Fezse presente também no A Alvorada, criado quase 3 décadas antes, no ano de 1907, na cidade de Pelotas e que de lá circulou por várias cidades da região e também alémfronteiras, até o ano de 1965. Assim como no periódico Orientacion, criado na cidade de Melo, em 1941, momento em que Acción não estava circulando, e se manteve ativo até 1945. Tais periódicos, assim como tantos outros espalhados pelos territórios de Brasil e Uruguai, estabeleceram laços simbólicos e objetivos com pessoas negras de outras partes do mundo, forjaram seus próprios sentidos de história, em que a liberdade e a coletividade eram traço marcante ao lado da sempre marcada gente da raça, transgredindo fronteiras nacionais e da representação nacional/regional. A transgressão de fronteiras é também entendida como no tocante à margem, dado que são experiências cujo epicentro, ou melhor, cujas redações e oficinas tipográficas encontravam-se distantes do grande centro 
urbano, como no caso de Pelotas em relação a Porto Alegre, ou de Melo em relação a Montevidéu, e mesmo de Jaguarão e Bagé em relação a Porto Alegre, visto que enquanto a primeira cidade teve notícias divulgadas nas folhas melenses, a segunda teve um suplemento no A Alvorada. Não obstante, a transgressão é também em termos de representações e imaginários regionais e nacionais, visto que ao longo do século XX e mesmo no XIX, tanto a província/estado do Rio Grande do Sul quanto a nação uruguaia consolidaram suas identidades como brancas, sobretudo, a partir do incentivo estatal à imigração de europeus datada no Rio Grande do Sul de 1850 e no Uruguai de $1890 .{ }^{11}$

Interpreto que, a partir desses elementos, posso estender o argumento da socióloga norte americana Patrícia Hill Collins acerca da outsider within ${ }^{12}$, para entender os homens (e por vezes mulheres) que escreviam nos periódicos e se faziam presentes nos clubes, por meio dos quais exteriorizavam demandas diversas. Ou seja, desde dentro das sociedades, fosse nacional ou local, mas das margens, estes intelectuais identificaram a racialização do negro que os irmanava para além das fronteiras nacionais. Gestaram formas de conceber o mundo e se manter conectado a ele, desde os seus pontos de vista, que por sua vez, deveriam ser incorporados no ponto de vista da nação, como continuaremos a ver nos próximos capítulos. Voltemos ao ano de 1935, para dar sequência no acompanhamento das complexidades entendidas aqui como evidências de um entendimento da história que tinha na racialização um eixo transnacional e que preencheu páginas de jornais no extremo sul do Brasil e no norte do Uruguai. Ressalto que o transnacional que eclode da noção de transfronteiriço é um marcador importante em minhas análises, principalmente sustentada nas interpretações de Micol Siegel quando informa que "História transnacional examina unidades que transbordam e infiltram-se através das fronteiras nacionais, unidades que podem ser tanto maiores ou menores do que o Estado-nação" (SIEGEL, 2005: 63). ${ }^{13}$

É importante não perder de vista que o periódico Acción tinha um objetivo bastante específico: ser porta-voz do comitê em prol da construção da sede própria do clube Centro Uruguay. Logo, as publicações deveriam estar vinculadas com o objetivo

\footnotetext{
${ }^{11}$ No Rio Grande do Sul a lei n. 229 de 4 de dezembro de 1851 marca o início do incentivo governamental à imigração europeia. No Uruguai a Ley básica de fomento de la inmigración data de 1890.

${ }^{12}$ Ao interpretar as mulheres negras e suas distintas construções de sentido advindas de suas experiências à margem a autora destaca que "muitas intelectuais negras, especialmente aquelas em contato com sua marginalidade em contextos acadêmicos, exploram esse ponto de vista produzindo análises distintas quanto às questões de raça, classe e gênero" (COLLINS, 2016).

13 Texto original: "Transnational history examines units that spill over and seep through national borders, units both greater and smaller than the nation-state".
} 
central. Não é demasiado interpretar que divulgar ideias compunha um sentido de construção de um lugar comum, neste sentido, mesmo que metaforizada, a sede do clube passava não só por questões físicas, mas também por ideais, modos de vida e a busca de uma unidade representativa, em que cada um destes tinha como fio transversal a ideia de raça a partir da superação da racialização que hierarquizava, inserindo-se em um ideal político central - a democracia. Já nos números que correspondem a $1^{\text {a }}$ época do jornal, 1934-1935, fica evidente a exteriorização de uma cultura política bastante arraigada em valores democráticos, em diálogo com os assuntos nacionais e com as experiências negras para além das fronteiras. As pessoas envolvidas no comitê, como Jacinto Ferrán, Morales Pérez e Páblo Alcántara, objetivavam passar a mensagem de que uma organização, pautada na ideia de raça negra, estava de acordo com os ditames democráticos. Certamente não por conta da discriminação reinante, mas por conta de entenderem a formação de uma coletividade como característica da democracia.

Os grupos negros, na ânsia por existir de forma plena, gestaram uma contra ideologia por meio das bases disponíveis e, se a raça os impedia de acessar espaços, porque não a utilizar como uma característica para forjar seus próprios espaços e por meio destes contrapor os estereótipos que fundamentavam as discriminações? Afinal, se teve um assunto que os periódicos negros não se privaram de discutir foi a discriminação com base na raça, como uma já consolidada produção historiográfica permite observar. Fortaleço esse argumento com base em dois exemplos, o primeiro está na terminologia acionada nas páginas de Acción como característica distintiva do seu fazer periódico: prensa racial. Tal caracterização extrapolou o jornal e referia outros colegas raciales, $(A$ Nuestros Colegas. Acción, 20 de junho de 1944: s/p.) sobretudo Nuestra Raza, mas também El Debate (fundado em 1931, em Montevidéu), El Peligro (fundado em 1935, em Rivera), Rumbos (fundado em 1938, em Rocha), Revista Ansina (fundada em 1939, em Montevidéu), Revista “Uruguay” (fundada em 1945, em Montevidéu), Rumbo Cierto (fundada em 1944, em Montevidéu) e Democracia (fundada em 1945, em Rocha). ${ }^{14}$ Extrapolou também as fronteiras da nação, como se observa na referência ao periódico La Verdad, editado em Buenos Aires, apresentado como “cultísimo quincenario porteño, es órgano de la colectividad de color buenosairence" (La Verdad. Acción, 30 de setembro

\footnotetext{
${ }^{14}$ As datas de criação dos jornais são inferidas das informações presentes nas matérias publicadas e de pesquisas. El Debate. Acción, 6 de julho de 1935; Saludando [La Verdad]. Acción, 16 de setembro de 1935, s/p; Lo que dicen de nosotros [El Peligro]. Acción, 15 de fevereiro de 1935, s/p; Revista "Uruguay". Acción, 28 de fevereiro de 1944, s/p. (ANDREWS, 2011: 134-154; LEWIS, 2003: 28).
} 
de 1935, capa). O segundo exemplo está na identidade conferida ao jornal em publicação oficial comemorativa, em razão do aniversário da Pátria, "De la Reseña Histórica de Cerro Largo" republicada no periódico, em que fez-se uma descrição acerca das organizações do departamento. No capítulo V, destinado às Instituciones Sociales y Gremiales o Centro Uruguay é apresentado como "representativo en Cerro Largo de la raza de color", no capítulo VI destinado ao periodismo, Acción é apresentado da seguinte forma:

Es un Periódico órgano de la raza negra, que aparece mensualmente, dirigido por el Sr. Juan Jacinto Ferrán.

'Acción' aparece actualmente en su segunda época. Colaboran en el destacados intelectuales de la raza de color. (Acción, 25 de agosto de 1946: $\mathrm{s} / \mathrm{p}$.)

Raza negra/raza de color era uma marcação corrente e comum, ao que tudo indica em nada invisível e não diluída por meio de outras expressões menos explícitas. E, assim se manteve durante todo o período da manutenção do jornal Acción. A Nota Editorial, da edição de 30 de novembro de 1934, destacou uma espécie de projeto do jornal e do Comitê, no qual se colocava como de defensa y protección a la Raza, ao final da nota destaca que tal pretensão, se alcançada positivamente por meio do Centro Uruguay legaria aqueles envolvidos um sentido de que "todos podemos estar satisfechos de nuestras organizaciones y ser dignos de alternar em el concierto social, como la raza que ha sabido colocar al Centro o más bien dicho a la Raza de color en la situación que le corresponde". Evidencia-se um discurso que se aproxima de uma ideia de raça social, enfatizando a contribuição da raça negra para a humanidade em contraposição a uma degenerescência ou hierarquização como de praxe nas teorias racistas. Dessa forma, o discurso do jornal aproxima-se do presente tanto nos escritos de W. E. B Du Bois (1999) acerca das gentes negras, quanto nos do intelectual negro haitiano Joseph Anténor Firmin sobre a "igualdade das Raças Humanas" (MARQUES, 2017). ${ }^{15}$

Em 1935 Acción passou a ser mensal e, por vezes, teve números duplos. Em geral, a $3^{\text {a }}$ página era ocupada por 'Notas Sociales', nas quais referenciava as pessoas que estavam em viagem sob o subtítulo viajeros. Nesta parte era enfatizado o trânsito pela fronteira, especialmente pelas cidades de Jaguarão, Bagé, Aceguá e Rio Branco, além de referir pessoas que se deslocavam para Pelotas, Porto Alegre e Montevidéu. De forma

\footnotetext{
${ }^{15}$ Os escritos de Firmin foram publicados em 1885, sob o título "De l'égalité des races humaines".
} 
ainda mais presente estava a referência à campaña, ou seja, localidades rurais presentes na região fronteiriça, dentre as quais sobressaiam as de Bagé. ${ }^{16} \mathrm{O}$ que é corroborado pelo estatuto do Centro Uruguay (1932) que, no $11^{\circ}$ artigo, informa que "Todos los socios de campaña designarán en la población una persona encargada de abonar las mensualidades y recibir las invitaciones y avisos".

As reportagens publicadas em Acción foram redigidas a partir da lente de raça negra/de color como marca distintiva. São sintomáticas as colunas assinadas por colaboradores e colaboradoras que evidenciam as leituras do passado assentadas em um fazer parte da construção da nação e as aspirações do presente e futuro, como no exemplo que segue:

Horas de lento dolor han agobiado a la Raza que un día vio pisoteados sus derechos por razones plenas de ignorancia y crueldad.

Y la noche sin estrella del desconocimiento quiso envolver en prolongado sueño los ideales de una raza fuerte que no negaría su cooperación al progreso. Fueron necesario múltiples esfuerzos para ahuyentar las sombras y vivir el día de la re redención, y mientras la noche reinaba, la humanidad recibía nuestra ofrenda de trabajo y dolor.

Con la aurora de la libertad la raza entonó el himno de sus triunfos y ascendiendo hacía las realizaciones demostró su fuerza.

Es por eso, que no debe existir en nosotros el desaliento, ni el temor al fracaso. Soñemos, forjemos un bello porvenir y sin cegarnos por los reflejos de lejanos espejismos hagamos pacientemente los trazos de la imagen simbólica de nuestros triunfos. En todas las etapas de nuestra marcha consideremos que no serán imposibles nuestra aspiraciones desde luego que son justas y van en acuerdo con los ideales del avance de todos los pueblos (Acción, 30 de novembro de 1934, s/p.).

É ilustrativa a leitura do período da escravidão e a perspectiva de desconstrução dos preconceitos racistas que se impuseram principalmente em fins do século XIX e princípios do XX. Permite observar que as discussões, após cerca de 100 anos da abolição formal da escravidão, ainda eram em torno da liberdade e dos direitos de cidadania em construção. Soma-se a isso a percepção da mobilização social como fundamental na

\footnotetext{
${ }^{16}$ Estas referências apareceram em todas as edições.
} 
ampliação dos direitos e aspirações em uma perspectiva de cultura comum que permite que todos os povos avancem em um signo próprio das noções de nacionalismo e modernidade. Um traço comum permeia as matérias publicadas no jornal, inclusive naquelas referentes às atividades sociais desenvolvidas no Centro Uruguay: a posicionalidade positiva de pessoas negras nas sociedades americanas apesar da discriminação racial reinante. Não sem considerar a perversidade da exclusão e seus malefícios, o que é evidenciado especialmente no que tange à invasão da Etiópia pelos italianos. $^{17}$

Em Pelotas, a situação não foi diferente, destaco aqui a voz pública que tal jornal manteve e a aproximação das bandeiras dos periódicos dessa região fronteiriça. No apanhado de memória que o jornal publica, quando de seus 49 anos (1956), denuncia a invasão da Etiópia, a manutenção do preconceito de cor e se coloca atento à discriminação reinante:

Nesses 49 anos, quase meio século de publicidade, em períodos diversos, apesar da indiferença de alguns, da incompreensão e da fatuidade de muitos, do negativismo da maior parte, justamente daqueles a quem servia, jamais mistificou o seu programa, desmentiu o lema com o qual se apresentou, quer defendendo Monteiro Lopes do esbulho que se pretendia fazer, cassando-lhe o mandato de deputado por ser NEGRO, quer contra a proibição a entrada de homens de côr e de suas famílias nos jardins Scotto da Praça Coronel Pedro Osório, nas cadeiras e camarotes do Teatro Guarani e do Capitólio, como o Tiro de Guerra em Pelotas, que não aceitava negros e mulatos nas suas fileiras. [...] Quer promovendo a campanha da fundação de uma "Frente Negra", nesta cidade, e atacando a incorporação da Abissínia a Itália pela prepotência, as ambições e arrogâncias de Mussoline. (Grifo do original. A Alvorada, 05 de maio de 1956)

$\mathrm{Na}$ esteira do alerta feito pela historiadora Wlamyra Albuquerque (2009: 206-208) ao identificar a referência o rei etíope Menelick II desde 1895 no jornal A Bahia e nos festejos de momo no pós-abolição baiano, a referência que fora destacada no A Alvorada e em Acción corrobora uma positividade da referência ao continente africano. Sem que isso significasse uma negação da identidade nacional brasileira ou uruguaia. Não

\footnotetext{
${ }^{17}$ O episódio deu-se entre os anos de 1935 e 1936, e, pode ser localizado na historiografia como Segunda
} Guerra Ítalo-Etíope. 
obstante, o periódico melense, assim como o pelotense, também estava atento aos impedimentos que alcançavam os negros na pequena cidade de Melo, e em uma destas denúncias se afigura aquilo que interpreto como a expressão do inadmissível em termos de racialização para aqueles sujeitos, que por sua vez permite compreender os motivos para criação e manutenção dos clubes para pessoas negras. A matéria que circulou na capa da edição de dezembro de 1949 fora intitulada "Línea de color - Café Central":

Este es el nombre de Café y Confitería instalado en las calles 25 de Mayo y Sarandí de nuestra ciudad, del cual es propietario el Sr. Efiro Díaz. ¿Qué tiene de extraordinario este café para que lo dediquemos esta nota? [...] lo extraordinario que tiene es la consigna dada a su personal de no servir a 'gente de color'.

El ser negro es el único obstáculo que existe para no ser servido en el mencionado café; sin embargo hemos visto atender junto a personas intachables que no merecen nuestro mayor respeto, a otras de dudosa moral y de sospechoso estado de salud, pero de tez blanca.

Lo interesante del caso, es que se utiliza una cuadra de la principal para la instalación de mesas para los servicios del café, suspendiendo el tráfico desde las 19 a las 24 horas, con un cartel que dice: 'Vía Blanca'.

La Constitución de la República establece que toda persona nacida dentro del territorio nacional tiene los mismos derechos, en consecuencia el criterio adoptado por el Sr. Efiro Díaz en su comercio es un hecho inconstitucional, ya que no es una sede social o desportiva que tiene su reglamentación interna, sino un lugar público, que además, (para obtener más ganancias) utiliza parte de una calle que por ser vía de tránsito, pertenece a todo el pueblo. [...] (Acción, s/d dezembro de 1949, capa).

A matéria refere aquilo que Thomas Holt (1995) nomeia por encontros de racialização. Não obstante a denúncia em si mesma denotativa da exclusão com base na raça é a ênfase ao caráter público do café que ressalvo como demonstrativo dos limites do tolerável. E, mais que isso, do recurso a lei e aos direitos de cidadania. Igualmente, é evidenciado que sedes sociais e desportivas, por conta de suas regulamentações internas, praticavam tal impedimento. Arrisco interpretar isso como a fluidez da racialização transfigurada nos direitos de propriedade, mas também na convivência bastante longínqua com aqueles que tinham o poder de realizar tal impedimento. Dentre os quais certamente 
estavam muitos dos patrões dos associados e associadas dos clubes e dos redatores dos jornais, que, ao viabilizarem as condições materiais de existência desses, acabavam por impedir um confronto direto acerca das dos impedimentos que também permitiam ou permitiriam caso algum desavisado ousasse adentrar nas sedes dos clubes da elite branca. Cabe assinalar que dois dos associados do Centro Uruguay durante todo o período da pesquisa, eram porteiros dos dois clubes de brancos daquela cidade. ${ }^{18}$ Os redatores forjavam assim uma história, desde a fronteira, que se conectava às histórias negras de outros locais e colocava em suspeição os ditames da sociedade branca e suas hierarquias raciais calcadas ora em prepotência, ambição e arrogância, ora em desrespeito ao espaço público. Ou seja, não existia nada de inato ou cientificamente justificado a não serem questões de exclusão advindas do social.

Ainda sobre a presença de coletividades negras na região fronteiriça, como previamente disposto no capítulo anterior e retomado aqui, a análise da $1^{\mathrm{a}}$ e $2^{\mathrm{a}}$ época de Acción evidencia uma série de laços com clubes e periódicos negros, sobretudo da região circunvizinha a Melo com ênfase aos Club Social Unión (Fraile Muerto), Club Manuel A. Ledesma - Ansina (Treinta y Tres) e Club Social y Cultural Renacimiento (Rocha) e da capital, o Centro Social 18 de Mayo. Estes laços eram bastante objetivos em termos de ações em prol de verbas para a aquisição da sede própria, como a experiência do Comité de Ayuda al Comité Pro-Edificio, que funcionava em Montevidéu (Acción, agosto - setembro de 1947: 1), permite evidenciar. Este era presidido por Pilar Barrios, vicepresidido por Trifón Macedo, secretariado por H. Pérez Morales e Elemo Cabral, como tesoureiros estavam Modesto de la Cruz e Juan j. Betervide, e, compunham ainda a diretoria os senhores Telésforo de los Santos, Liguizamón Montero, Julián M. Fernández, Ceferino Nieres, ${ }^{19}$ Juan C. Sosa, Alfonso Sosa, Pablo Coles. Esta iniciativa de auxílio financeiro, mas também de compartilhamento de ideais foi conteúdo da matéria de capa do número 1 da $3^{\text {a }}$ época, 30 de agosto de 1947, visto que encerrou suas atividades em decorrência de comentários maldosos, rebatidos no número seguinte, sob a assinatura de Juan Jacinto Ferrán, Pablo Alcántara, Telésforo Machado e Carlos M. Pérez Morales, que por sua vez compunham a comissão diretiva do Comité Pro Edificio.

Mas os comentários vinham de quem? Aparentemente tinham eco e, é ao observar as linhas de outro periódico que a resposta parece afigurar-se. No entanto, antes é preciso

\footnotetext{
18 Juan Jacinto Ferrán e Juan Jacinto Silveira, respectivamente do Centro Unión Obrero e Club Unión, respectivamente.

19 Oriundo de Melo.
} 
fazer alguns apontamentos a partir de Acción. Se por um lado é fácil evidenciar uma ligação da experiência negra na região fronteiriça com a da capital do país, por outro permite destacar que a capital era de fato um pólo de atração para a população negra em busca de melhores condições de vida. Porém, a vida lá também era marcada por racialização, o que fazia com que das páginas dos jornais se convocasse à união melenses, montevideanos e uruguaios de outras cidades a fim de auxiliar no progresso daquela comunidade que permanecia em Melo. Assim, os auspícios em prol da construção da sede do Centro Uruguay nos legam bem mais que um conteúdo meramente lúdico.

Enquanto porta-voz do Comité, o jornal parece fundir-se com a diretoria do clube. Suas ações aconteciam na sede do clube e prezavam sempre pelo puritanismo com relação aos hábitos e manifestações externas da organização, como veremos na última parte desta tese. O mesmo se verifica nas relações estabelecidas com as localidades de Fraile Muerto e Treinta y Três, por exemplo, assim como nos destaques conferidos a pessoas e episódios que extrapolam em muito o espaço da cidade de Melo, da tão referida campaña, e da fronteira de uma forma geral. Foi a partir da $2^{\mathrm{a}}$ época de Acción, em 1944, que começaram a aparecer as divergências internas do grupo. Nesta época, o jornal manteve estrutura semelhante, porém começou a publicar colunas referentes a outras cidades, como Noticias de Treinta Y Tres e Noticias de Montevideo.

A notícia publicada na edição de 20 de junho de 1944 apresenta o início daquilo que veio a se constatar como uma divergência de opiniões e ações por parte de representantes e membros da comunidade negra melense, que participavam do clube: o surgimento de um periódico dirigido por Carlos M. Pérez, ex-diretor do Acción, e que mereceu uma nota muito pequena frente às demais que o jornal costumava divulgar, mesmo quando não eram notícias envolvendo os conrazaneos (Acción, junho de 1944: s/p.). Nesta edição, publicou-se a seguinte nota sob o título Orientacion: "Bajo la misma dirección del destacado periodista Sr. Carlos M. Pérez. Morales, reapareció en los últimos días del mes de Mayo el colega con cuyo nombre intitulamos estas líneas." (Acción, junho de 1944, s/p). Na sequência, apresentou-se um agradecimento por saudação recebida e estabeleceu-se a prática da troca de exemplares, como de praxe entre os periódicos.

O jornal Orientacion foi publicado em Melo, entre 1941 e 1945 . Na $1^{\text {a }}$ época (1941-1944) adotou três identificações: Órgano de la Colectividad de Color (1941-1943), Órgano de la Raza Negra Departamental (1943-1944) e Periodico Racial (Orientacion, agosto de 1944: 1). Na 2 a época o jornal autodenominava-se Periodico de la Raza Negra 
(Orientacion, junho de 1945: 1). Apresentava em cada edição um artigo relacionado aos problemas encontrados pelos negros nos espaços em que era veiculado, mas também assuntos concernentes aos negros em perspectiva diaspórica, com destaque para a Etiópia e Estados Unidos, o que pode justificar o lema: Unidad - Solidariedad - Esfuerzo. Teve periodicidade quinzenal entre 1941 e 1944, período em que o Acción não estava circulando. A partir de 1944, passou a ser mensal e, por vezes, apresentou números duplos.

A direção de Orientacion era executada por Carlos M. Pérez, o mesmo diretor da primeira época de Acción e membro da comissão diretiva do Comité Pro Edifício, como relatado algumas linhas atrás. A administração estava a cargo de José Ramón Fernández, também associado do Centro Uruguay. O periódico parece ser fruto de uma dissidência dentro do jornal anterior, visto que os diretores eram membros do Centro Uruguay e o jornal defendia os interesses do clube, nitidamente, apresentado como central para a coletividade negra de Melo. Pérez e Ferembaro foram da diretoria do Centro durante todo o período compreendido pela existência desses dois jornais (1934-1952). Já no editorial do $1^{\circ}$ exemplar, é possível inferir que existiam diferenças nas perspectivas de ação da coletividade negra melense. Esse editorial foi intitulado "Estamos de Nuevo en la Brecha" e reconhecia o papel precursor de Acción na prensa racial do departamento. $\mathrm{O}$ jornal surgiu sete anos após o aparecimento daquele.

Orientacion tinha correspondente em Rio Branco e noticiava atividades do Club 24 de Agosto, de Jaguarão. Somado a esses elementos a passagem a seguir, presente na primeira página do número 1, é bastante ilustrativa:

[...] surge a la vida nuestro órgano de publicidad que es una tribuna al servicio de los ideales de la raza y por la exaltación de los mismos, una tribuna periodística que era una sentida necesidad en nuestro medio para combatir los males existentes en nuestra colectividad y para combatir prejuicios que nunca se justificarán. [...] sus columnas estarán abiertas para todos los representantes de la raza, sin distingos de ninguna índole (Orientacion, 12 de outubro de 1941: 1).

Na edição seguinte já começa a figurar no jornal, alçado ao posto de voz pública, aquela que parece ter sido sua principal bandeira: uma rua com o nome de Manuel Antonio Ledesma (Ansina), o fiel companheiro do prócer da independência uruguaia, 
Artigas. A voz pública dos jornais permite delinear alguns contornos daquela comunidade que era simultaneamente imaginada e delimitada de forma objetiva, tal como alerta Cristian Castro, ao utilizar a imprensa negra de São Paulo e Chicago como lente de análise daquilo que ele, também calcado na análise de Gilroy, apresenta como "una historia transnacional de la afro-modernidad en América" (CASTRO, 2010).

A negritude pautada em um orgulho de ser negro observada desde a imprensa negra da região de fronteira Brasil-Uruguai conferia uma identidade que via nos corpos negros, que não necessariamente haviam nascido no solo oriental ou sulino/brasileiro, iguais desta vasta comunidade transnacional. Essas pessoas viam na cor da pele em seus mais diferentes matizes um elemento de identificação, transformado em um instrumento de luta forjado na adversidade das Américas. Marcada por uma negação do lugar de americanos e cidadãos plenos às pessoas negras que, por sua vez, compreendiam que a ideia de raça que os outros reservavam a eles lhes impunha essa barreira. O que bem pode ser identificado como um aspecto daquilo que a pesquisadora Lélia Gonzalez, ao referir à experiência negra no Brasil, mas sem perder de vista as vivências em outros contornos nacionais, sintetizou como: "a luta do povo negro do Brasil é um aspecto de uma luta muito maior: a luta dos negros do mundo". (GONZALEZ, 1985: 132)

E, foi por meio das páginas da imprensa negra que as coletividades negras mostraram-se conscientes da realidade de seus co-irmãos e conrazaneos em outras partes do mundo. Em pleno momento de circularidade das teorias raciais e das teses eugênicas se autoidentificavam como parte das sociedades humanas, sobretudo, na defesa inconteste e ferrenha da autonomia etiópica quando da invasão italiana em fins da década de 40, afinal, como assinalado nas páginas do jornal Acción, no momento de guerra se unem em um mesmo sentimento e desejo todos "espíritus justicieros del mundo, para condenar sin reservas el bombardeo de poblaciones desarmadas y el sacrificios de mujeres y niños que aunque sean negros, son del mismo barro humano de las mujeres y de niños de todas las zonas".

Todo esse conteúdo presente nas páginas da imprensa negra expressa parte das evidências de como os jornais também forjaram suas escritas da história, exercendo uma voz que ecoava por meio de uma tribuna pública da qual recusava-se o lugar do negro como ser meramente "bonzinho" ou inexistente, denunciava-se os problemas impostos aos negros e não os negros enquanto problema, configurando uma realidade distinta daquela que ecoava nas vozes oficiais do Estado Nação e tecendo uma narrativa por meio de seus próprios termos. 


\section{Fontes}

A Alvorada. Pelotas, números esparsos 1912-1944, 1947-1956.

Acción. Melo, 1934-1952.

Estatutos generales del Centro Uruguay. Melo, 1932. Regulamento Interno del "Centro Uruguay".

Orientacion. Melo, 1941-1945.

\section{Referências Bibliográficas}

ALBUQUERQUE, Wlamyra R. de. (2009). O jogo da dissimulação: Abolição e cidadania negra no Brasil. São Paulo: Cia das Letras.

ANDREWS, George Reid. (2011). Negros en la nación blanca: historia de los afrouruguayos. Montevideo (Uruguay): Librería Linardi y Risso.

BASTIDE, Roger. (1973) A Imprensa Negra do Estado de São Paulo. In: BASTIDE, Roger. Estudos afro-brasileiros. São Paulo: Perspectiva, 1973, p. 129-156.

BERSTEIN, Serge. A cultura política. In: RIOUX, Jean-Pierre \& SIRINELLI, JeanFrançois. Para uma História Cultural. Lisboa: Estampa, 1998, pp. 349-363.

BURGUEÑO, Cristina. (2007). Virginia Brindis de Salas: La Voz de un 'Yo' Afro. Negritud, v.1, n.1, p. 281-289.

CASTRO, Cristian. (2010). Exploraciones para una historia transnacional de la afromodernidad en América. Chicago y Sao Paulo, 1900-1940. Revista de Historia Iberoamericana, v. 3, n. 1, p.33-49.

CHALLOUB, Sidney. (2010). Precariedade estrutural: o problema da liberdade no Brasil escravista (século XIX). História Social, n. 19, p. 33- 62, 2010.

COLLINS, Patricia Hill (2016). Aprendendo com a outsider within: a significação sociológica do pensamento feminista negro. Sociedade e Estado, v. 31, n. 1, pp. 99127.

CÔRTES, Giovana Xavier da Conceição. (2012) Brancas de almas negras? Beleza, racialização e cosmética na imprensa negra pós-emancipação (EUA, 1890-1930). Campinas (SP): Universidade Estadual de Campinas. Tese (Doutorado em História).

DAVIS, Angela Y. (2009). A Democracia da Abolição - para além do império, das prisões e da tortura. Rio de Janeiro: DIFEL.

DECOSTA-WILLIS, Miriam (2003). Daughters of the diaspora: Afra-Hispanic writers. Ian Randle Publishers.

DU BOIS, W. E. B. (1999). As almas da gente negra. Rio de Janeiro: Lacerda.

FERRARA, Miriam Nicolau. (1986). A imprensa negra paulista (1915-1963). São Paulo: Universidade de São Paulo. Dissertação (Mestrado em História).

GOLDMAN, Gustavo (2015). Negros modernos: música, territorio y asociacionismo al sur de la ciudad de Montevideo a fines del siglo XIX. Boletin de Musica, n. 41, pp. 49-65.

(2016). Los otros ciudadanos: Asociacionismo, prensa y política de los negros montevideanos a fines del siglo XIX. Claves Revista de Historia, n. 2, pp. 175-198.

GONZALEZ, Lélia. (1985) The unified black movement: a new stage in black political mobilization. In: FONTAINE, Pierre-Michel. Race, class and power in Brazil. Los Angeles: UCLA Center for Afro-American Studies, pp. 120-134. 
HOLT, Thomas. C. (1995). Marking: race, race-making, and the writing of history. The American Historical Review, vol. 100, n. 1, pp. 1-20.

LEWIS, Marvin A (2003). Afro-Uruguayan literature: post-colonial perspectives. London: Bucknell University Press.

LIMA, Henrique Espada. (2005). Sob o domínio da precariedade: escravidão e os significados da liberdade de trabalho no século XIX Topoi, vol. 6, n. 11, pp. 289326.

Loner, Beatriz Ana (2001). Construção de classe: operários de Pelotas e Rio Grande, 1888-1930. Pelotas: Editora e Gráfica Universitária-UFPel/Rede Unitrabalho. (2009) A rede associativa negra em Pelotas e Rio Grande. In: Silva, Gilberto

Ferreira da; Santos, José Antônio dos. RS Negro: cartografias sobre a produção do conhecimento. Porto Alegre: EDIPUCRS, pp. 246-261. \& Gill, Lorena. (2009) Clubes carnavalescos negros na cidade de Pelotas. Estudos Ibero-Americanos. Porto Alegre, vol. 35, n. 1, pp. 145-162.

(2011) Antônio: de Oliveira a Baobab. In: Gomes, Flávio; Domingues, Petrônio.

Experiências da emancipação: biografias, instituições e movimentos sociais no pósabolição (1890-1980). São Paulo: Selo Negro, pp. 109-136.

MARQUES, Pâmela Marconatto. (2017). “'Nou led, nou la!' Estamos feios, mas estamos aqui!" Assombros haitianos à retórica colonial sobre pobreza. Porto Alegre: Universidade Federal do Rio Grande do Sul, 2017. Tese (Doutorado em Sociologia).

PEREIRA, Amilcar Araújo. (2013) O mundo negro: relações raciais e a constituição do movimento negro contemporâneo no Brasil. Rio de Janeiro: Pallas; FAPERJ.

PINTO, Ana Flávia Magalhães. (2010). Imprensa negra no Brasil do século XIX. São Paulo: Selo Negro.

(2014). Fortes laços em linhas rotas: literatos negros, racismo e cidadania na segunda metade do século XIX. Campinas (SP): Universidade Estadual de Campinas. Tese (Doutorado em História).

RODRÍGUEZ, Romero Jorge. (2006). Mbundo, Malungo A Mundele: Historia del movimiento Afrouruguayo y sus alternativas de desarrollo. Montevideo (UY): Rosebud Ediciones.

SANTOS, José Antonio dos. (2011). Prisioneiros da história. Trajetórias intelectuais na imprensa negra meridional. Porto Alegre: Pontifícia Universidade Católica do Rio Grande do Sul. Tese (Doutorado em História).

SANTOS, José Antonio dos (2003). Raiou a Alvorada: Intelectuais negros e imprensa. Pelotas: Editora e Gráfica Universitária-UFPel.

SEIGEL, Micol. (2005). Beyond compare: comparative method after the transnational turn. In: Radical History Review, n. 91, pp. 62-90.

SERRAT, Alberto Brítos (1990). Antologia de poetas negros uruguayos. Montevideo (Uruguay): Ediciones Mundo Afro.

SILVA, Fernanda Oliveira da. (2017). As lutas políticas nos clubes negros: culturas negras, racialização e cidadania na fronteira Brasil-Uruguai no pós-abolição (18701960). Tese (Doutorado em História). Universidade Federal do Rio Grande do Sul, Porto Alegre. 
Artigo recebido em 30 de abril de 2018.

Aprovado em 30 de maio de 2018.

DOI:10.12957/intellectus.2018.35650 